EESTI NSV TEADUSTE AKADEEMIA TOIMETISED. 30. KOIDE KEEMIA. 1981, NR. 4

ИЗВЕСТИЯ АКАДЕМИИ НАУК ЭСТОНСКОН ССР. ТОМ 30 Химия. 1981, $\mathrm{No} 4$

Линда ПОБУЛЬ

\title{
ДОПОЛНЕНИЯ К КОЛБОВОМУ МЕТОДУ ШЁНИГЕРА И ЕГО ИСПОЛЬЗОВАНИЕ ДЛЯ ОПРЕДЕЛЕНИЯ СЕРЫ В ОРГАНИЧЕСКИХ СОЕДИНЕНИЯХ
} Linda POBUL. TAIENDUSI SCHONIGERI KOLVIMEETODILE NING SELLE KASUTAMINE VAAVLI
MAARAMISEKS ORGAANILISTES OHENDITES

Linda POBUL. THE USE OF MODIFIED OXYGEN FLASK (SCHONIGER) METHOD FOR SULPHUR DETERMINATION IN ORGANIC. COMPOUNDS

\section{(Представил О. Эйзен)}

Наиболее простой метод определения галогенов и серы в органических соединениях - т. н. колбовый метод Шёнигера ['], который состоит в том, что навеска нсследуемого вещества в кусочке беззольной фильтровальной бумаги сжигается в находящейся в колбе корзинке из платиновой сетки в атмосфере кислорода. В образовавшемся при горении продукте определяется содержание нужного элемента [ $\left.{ }^{2}\right]$. Различными исследователями для этой цели употребляется аппаратура различной конструкции $\left[{ }^{3-6}\right]$. Недостатком всей применяемой аппаратуры является то обстоятельство, что бумага с исследуемой пробой поджигается вне колбы.

Используемая аппаратура (рисунок, $a$ ) состоит из 600-миллилитровой или большей по объему колбы Эрленмейера со шлифованным горлом (шлиф 29) и стеклянной пробкой с краном. В пробку впаяны две платиновые проволочки диаметром $0,8-1,0$ мм. Длина проволочки $150-200$ мм в зависимости от объема употребляемой колбы. Концы проволочек выступают приблизительно на 10 мм от поверхности пробки, с помощью прикрепляемых к ним «крокодилов» они присоединяются к источнику электрического тока низкого напряжения. К внутренним концам проволочек в колбе монтируется корзинка из платиновой сетки размером $10 \times 15$ мл. В данном случае использовалась платиновая сетка из проволочек диаметром 0,1 мм, имевшая 1024 отверстия на квадратный сантиметр. Конец одной проволоки соединяется с корзинкой более тонкой (диаметром 0,3-0,4 мм) платиновой проволокой, которая используется для зажигания. Она сгибается в виде дуги над корзинкой. Мешочек, свернутый из треугольной фильтровальной бумаги (рисунок, б), вместе с навеской исследуемого вещества помещают в корзинку таким образом, чтобы острый конец бумаги касался зажигательной проволоки. Так как зажигательная проволока в процессе работы время от времени перегорает, то ее концы присоединяют таким образом, чтобы ее можно было заменять. Чтобы зажечь фильтровальную бумагу, нужно лишь на мгновение пропустить через систему ток 
$a$ - Аппаратура для сжигания пробы. 1 - платиновая проволочка диаметром $0,8-1,0$ мл; 2 корзинка из платиновой сетки; 3 - зажигательная проволока диаметром $0,3-0,4$ м.м. $6-$ Бумага для сжигания пробы.

выо́ранного низкого напряжения. В данном случае ток напряжением около $6-7 B$ получают соответствующим трансформированием тока городской сети с использованием включателя типа МП-230.

Колба заполняется кислородом лишь после того, как корзинка вместе с навеской уже вложена в колбу, в которой находится соответствующий определяемому элементу реактив $\left[{ }^{2}\right]$. Через отверстие стеклянного крана, диаметр которого равен $6 \rightarrow 8$ мм, вводится стеклянная трубка, с ее помощью колба заполняется кислородом. Вслед за этим сжигают пробу, после чего взбалтывают находящийся в колбе реагент так, чтобы стенки колбы, корзинка и проволочки были полностью смочены. Затем колбу оставляют на $30-$ 40 мин в покое. За это время колбу пару раз взбалтывают. Определяемый элемент анализируется далее согласно соответствующей методике $\left[{ }^{2}\right]$. При определении серы в качестве растворнтеля употребляли изопропиловый спирт, который вводили в колбу через отверстие в кране таким образом, чтобы он обтекал всю поверх-

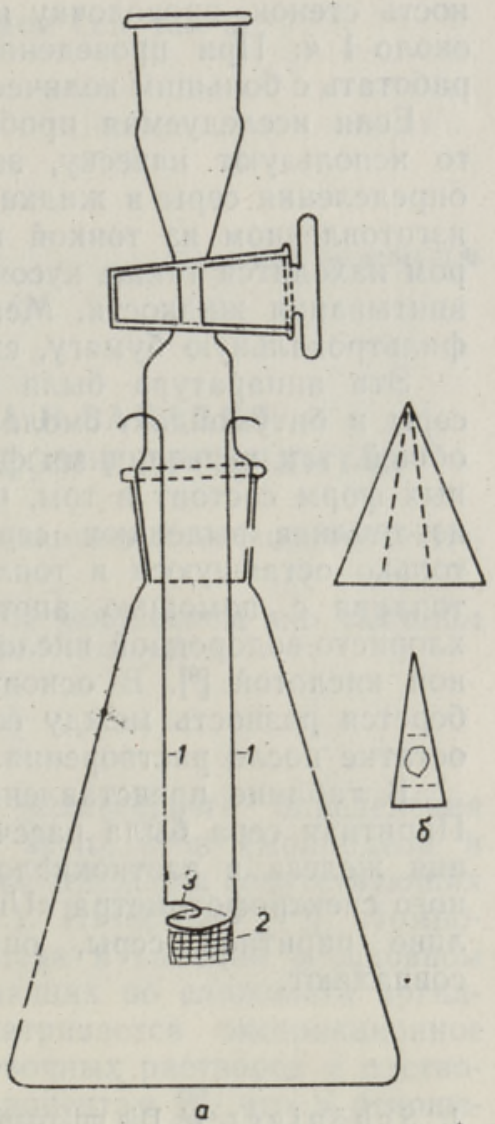

Содержание серы в различных горючих сланцах

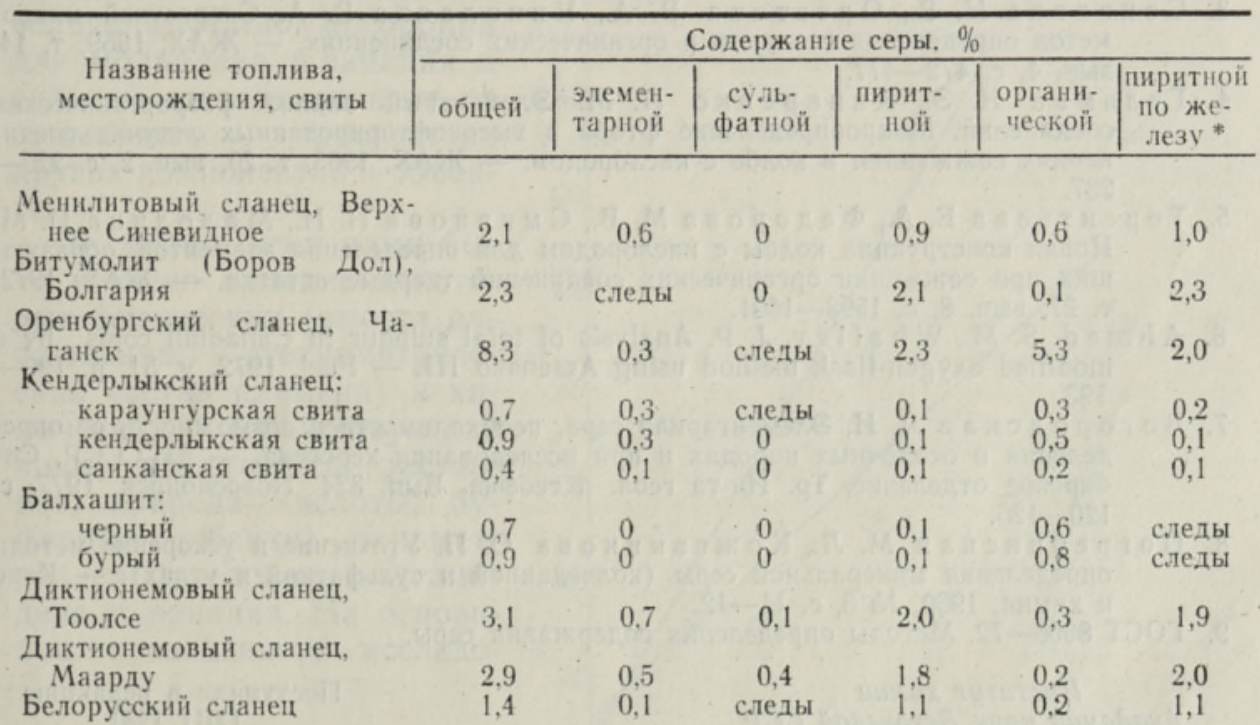

* Железо в растворе определялось методом атомно-абсорбционной спектрофотометрии на спектрофотометре «Unikam SP1900», 
ность стенок, проволочку и корзинку. Продолжительность всего опыта около 1 . При проведении массовых анализов можно одновременно работать с большим количеством колб.

Если исследуемая проба - твердое или сильно вязкое вещество, то используют навеску, завернутую в фильтровальную бумагу. Для определения серы в жидких веществах используют навеску в мешочке, изготовленном из тонкой полиэтиленовой пленки $(5 \times 10$ мм $)$, в котором находится также кусочек фильтровальной бумаги или поролон для впитывания жидкости. Мешочек с пробой, завернутый в треугольную фильтровальную бумагу, сжигают.

Әта аппаратура была использована для определения содержания серы в битумоидах, смолах и твердом топливе. Определяли серу как общей, так и различных форм. Суть метода определения серы различных форм состоит в том, что с помощью того или иного растворителя из топлива выделяют серу соответствующей формы и определяют только оставшуюся в топливе серу. Әлементарную серу. выделяют из топлива с помощью ацетона [ $\left.{ }^{7}\right]$, сульфатную - водным раствором хлористо-водородной кислоты [8], а пиритную - путем обработки азотной кислотой [9]. В основу расчета количества серы каждой формы берется разность между ее содержанием в пробе до растворения и в остатке после растворения.

В таблице представлены результаты определения серы всех форм. Пиритная сера была рассчитана также и путем определения содержания железа в азотнокислом растворе с помощью атомно-абсорбционного спектрофотометра «Unikam SP1900». Данные о содержании в топливе пиритной серы, определенные двумя различными методами, совпадают.

\section{ЛИ Т Е Р А Т У А}

1. S chön i ger, W. Die mikroanalytische Schnellbestimmung von Halogenen und Schwefel in organischen Verbindungen, - Microchim. Acta, 1956, S. 869-876.

2. Климова В. А. Основные микрометоды анализа органических соединений. М., 1975 , c. $110-121$

3. Соколова Н. В., Орестова В. А., Николаева В. А. Скоростной микрометод определения галоидов в органических соединениях. - ЖАХ, 1959, т. 14, вып. 4 , с. $472-477$.

4. Гельм ан Н. Э., Ки п а ренко Л. М. Элементный анализ фторорганических соединений. Микроопределение фтора в высокофторированных летучих соединениях сожжением в колбе с кислородом. - ЖАХ, 1965, т. 20, вып. 2, с. 229237.

5. Те рентьева Е. А., Федорова М. В., Смирнов а Н. Н., Малолина П. М. Новая конструкция колбы с кислородом для определения элементов, образующих при сожжении органических соединений твердые остатки. - ЖАХ, 1972, т. 27 , вып. 8 , с. $1598-1601$.

6. Ahm ed, S. M., Wh a lley, J. P. Analysis of total sulphur in Canadian coals by a modified oxygen-flask method using Arsenazo III. - Fuel, 1972, v. 51, p. 190193.

7. Богородск ая Л. И. Элементарная сера, необходимость и возможность ее определения в осадочных породах и при исследовании керогена. - АН СССР, Сибирское отделенне. Тр. Ин-та геол. и геофиз. Вып. 334. Новосибирск, 1977, с. $120-125$.

8. Погребин ская М. Л., Кожевников а О. П. Уточнение и ускорение метода определения минеральной серы (колчеданной и сульфатной в углях). - Кокс и химия, 1960 , № 6, с. 11-12.

9. ГОСТ 8606-72. Методы определения содержания серы.

Ннститут химии

Академии наук Эстонской ССР
Поступила в редакцию

17/II 1981 